Cucchi, M and Samuel, S

Influence of the exhaust gas turbocharger on nano-scale particulate matter emissions from a GDI spark ignition engine.

Cucchi, M and Samuel, S (2014) Influence of the exhaust gas turbocharger on nano-scale particulate matter emissions from a GDI spark ignition engine. Applied Thermal Engineering, 76. pp. 167-174.

doi: 10.1016/j.applthermaleng.2014.11.002

This version is available: https://radar.brookes.ac.uk/radar/items/8ad12a1c-4b0d-4dd6-92af-8df5f44b59f1/1/

Available on RADAR: November 2016

Copyright (C) and Moral Rights are retained by the author(s) and/ or other copyright owners. A copy can be downloaded for personal non-commercial research or study, without prior permission or charge. This item cannot be reproduced or quoted extensively from without first obtaining permission in writing from the copyright holder(s). The content must not be changed in any way or sold commercially in any format or medium without the formal permission of the copyright holders.

This document is the post print version of the journal article. Some differences between the published version and this version may remain and you are advised to consult the published version if you wish to cite from it. 


\section{Elsevier Editorial System(tm) for Applied Thermal Engineering Manuscript Draft}

Manuscript Number: ATE-2014-5921R1

Title: Influence of the Exhaust Gas Turbocharger on Nano-Scale Particulate Matter Emissions from a GDI Spark Ignition Engine

Article Type: Research Paper

Keywords: particulate matter number emissions, turbocharger, gasoline direct-injection engine, differential mobility spectrometer

Corresponding Author: Dr. Stephen Samuel,

Corresponding Author's Institution: Oxford Brookes University

First Author: Matteo Cucchi, MSc

Order of Authors: Matteo Cucchi, MSc; Stephen Samuel, Dr

Abstract: The influence of the exhaust gas turbocharger on nano-scale Particulate Matter (PM) number emissions from a Gasoline Direct Injected (GDI) engine is investigated at fixed exhaust gas dilution ratio for a matrix of three engine speeds and four engine load operating points. Experimental repeatability is assessed by means of the Coefficient of Variation (CoV) from three independent measurements for every test point. A hypothesis test on the difference between total number count before and after the turbine shows that there are statistically relevant variations for most operating points. A reduction in PM total number count at low load is observed, and an increment at high load. It is conjectured that as fuel injection pressure and duration increase with load, a larger share of volatile particulate matter is produced, which then undergoes nucleation as the exhaust gas expands through the turbine. At the same time, the centrifugal action within the turbocharger is believed to promote particle agglomeration and growth, and fragmentation of micro-scale particles. Experiments with variable dilution ratio at a fixed engine test point show that changes in dilution ratio affect repeatability of the emissions measurements only marginally. Yet, a hypothesis test on the variation of total number count with dilution shows that PM number counts are systematically affected by changes in dilution ratio. Furthermore, a hypothesis test also shows that the impact of the turbocharger on total number emissions is statistically relevant regardless of the dilution ratio adopted. 
*Highlights (for review)

\section{Highlights:}

- $\quad$ Nano-scale PM from a TGDI engine is measured with a particulate spectrometer - Hypothesis test proves statistically relevant differences in PM across the turbine

- $\quad$ As engine load increases PM number concentrations increase across the turbine

- $\quad$ Particles nucleation and agglomeration are thought to occur across the turbine

- Hypothesis test proves turbine influence regardless of exhaust gas dilution level 


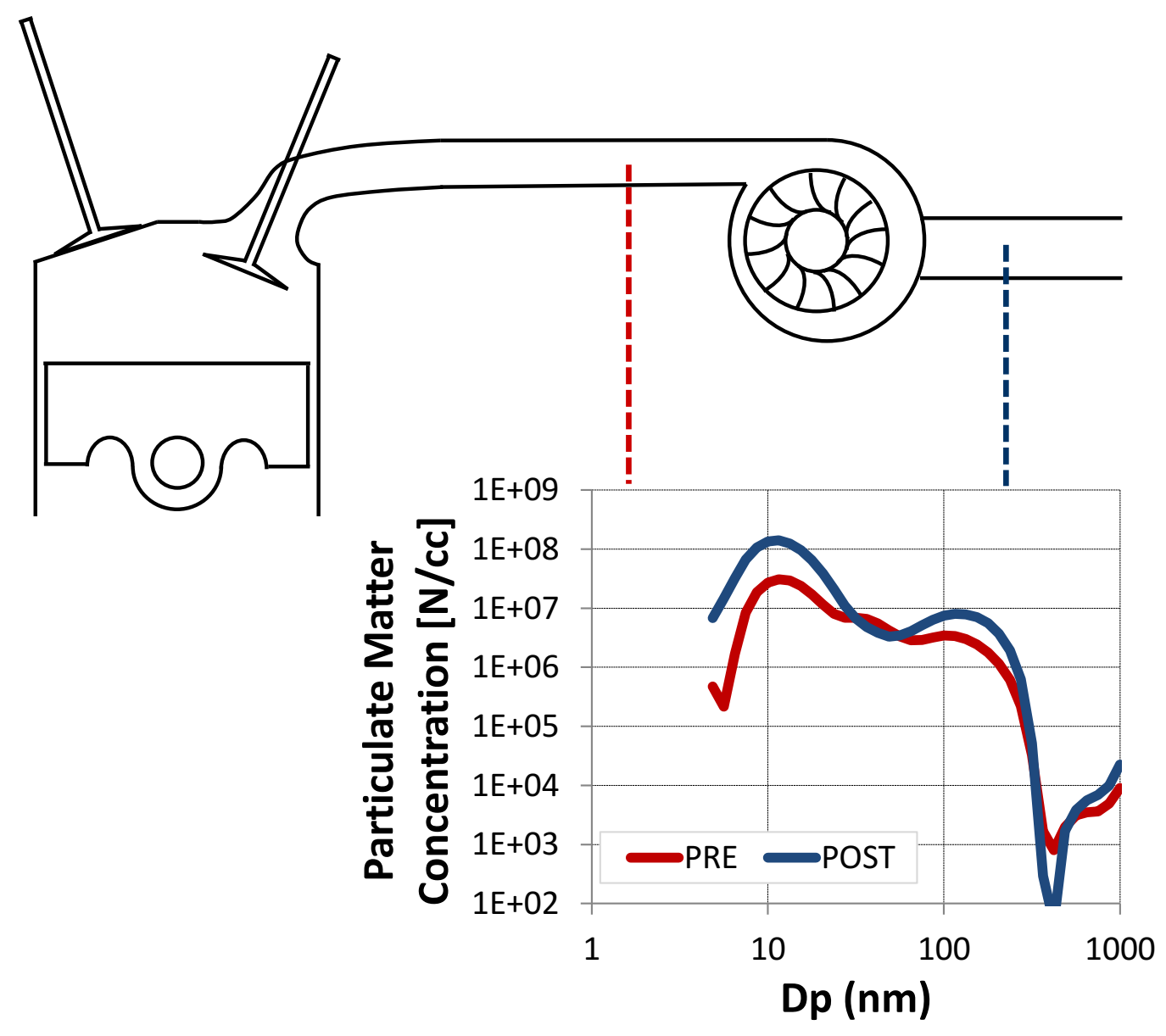




\title{
Influence of the Exhaust Gas Turbocharger on Nano-Scale Particulate Matter Emissions from a GDI Spark Ignition Engine
}

\author{
Abbreviated title: Turbocharger Influence on PM Emissions
}

\author{
Matteo Cucchi, Stephen Samuel \\ Department of Mechanical Engineering and Mathematical Sciences, Oxford Brookes University, Oxford, UK
}

\begin{abstract}
Address correspondence to Stephen Samuel, Faculty of Technology, Design \& Environment, Department of Mechanical Engineering and Mathematical Sciences, Oxford Brookes University, Wheatley Campus, OX33 1HX UK.

Phone: + 441865 483513; email: s.samuel@brookes.ac.uk
\end{abstract}

\begin{abstract}
The influence of the exhaust gas turbocharger on nano-scale Particulate Matter (PM) number emissions from a Gasoline Direct Injected (GDI) engine is investigated at fixed exhaust gas dilution ratio for a matrix of three engine speeds and four engine load operating points. Experimental repeatability is assessed by means of the Coefficient of Variation (CoV) from three independent measurements for every test point. A hypothesis test on the difference between total number count before and after the turbine shows that there are statistically relevant variations for most operating points. A reduction in PM total number count at low load is observed, and an increment at high load. It is conjectured that as fuel injection pressure and duration increase with load, a larger share of volatile particulate matter is produced, which then undergoes nucleation as the exhaust gas expands through the turbine. At the same time, the centrifugal action within the turbocharger is believed to promote particle agglomeration and growth, and fragmentation of micro-scale particles. Experiments with variable dilution ratio at a fixed engine test point show that changes in dilution ratio affect repeatability of the emissions measurements only marginally. Yet, a hypothesis test on the variation of total number count with dilution shows that PM number counts are systematically affected by changes in dilution ratio. Furthermore, a hypothesis test also shows that the impact of the turbocharger on total number emissions is statistically relevant regardless of the dilution ratio adopted.
\end{abstract}

KEYWORDS: particulate matter number emissions, turbocharger, gasoline direct-injection engine, differential mobility spectrometer

\section{NOMENCLATURE}

Cl
CMD
CoV
$d_{C M D_{k}}$
$\mathrm{DMS}$
$\Delta N / c c$
$\Delta N / c c_{l o g}$
$D_{p}, d_{p}$
$\mathrm{DR}$
GDI
$n_{k}$
$\mathrm{PM}$
$\mathrm{PMP}$
preTC
postTC
SOF
$V_{P M}$

Compression Ignited

Count Mean Diameter

Coefficient of Variation

CMD of the $\boldsymbol{k}$-th discretised size class

Differential Mobility Spectrometer

Change in particulate matter number concentration across the turbine

Logarithmic variation in particulate matter number concentration across the turbine

Particle aerodynamic diameter

Dilution Ratio

Gasoline Direct Injection

Number concentration of the $\boldsymbol{k}$-th discretised size class

Particulate Matter

Particulate Measurement Programme

Suffix identifying a variable being measured before the turbocharger (at the turbine entry)

Suffix identifying a variable being measured after the turbocharger (at the turbine outlet)

Soluble Organic Fraction

Particulate matter volume 


\section{INTRODUCTION}

In an attempt to improve the efficiency, to increase the performance and to limit the fuel consumption and emissions of modern automobiles, the use of an exhaust gas turbocharger in Gasoline Direct Injected (GDI) engines has become a popular solution that has been adopted by numerous automotive manufacturers [1]. On the other hand, though, direct injection leaves a much shorter time for thorough fuel vaporisation and for mixture preparation, which results in higher Particulate Matter (PM) emissions [2,3]. Given this substantial increment, and considering the impact of PM on human health [4], PM emissions from GDI engines need to be studied closely.

In the recent years, research has focused its attention on the contribution on PM emissions of some exhaust after-treatment devices along the exhaust line. For GDI engines in particular, the catalytic converter was shown to have a profound influence on the particle size distributions of PM measured at its inlet and outlet. Research by Whelan et al. [5] proved that particle agglomeration and growth are phenomena which can alter the PM population balance in devices which handle particle-laden gases. These considerations acquire even further significance if the Euro-VI Emission Regulations for the European Market are accounted for. For the first time in Europe these Standards will introduce stringent limits on PM number emissions from GDI engines, on a par with the maximum levels allowed to Compression Ignited $(\mathrm{Cl})$ engines, in addition to the already existing limits in terms of PM mass emissions [6-8]. Unlike mass, PM number count is not conserved [9], hence engine manufacturers will need to pay careful attention to the optimisation of engine design and calibration in order to meet the new tailpipe-out requirements. Recent studies showed that the current GDI technology allows to meet the PM mass limits but the PM number count limits are often exceeded [10,11].

The exhaust gas turbocharger, being a high-speed rotating device which interferes directly with the exhaust gas from the engine, can itself have a substantial impact on the size distributions of PM as the exhaust gas flows through, potentially altering the tailpipe-out PM number count of the engine it is matched to. Despite this, little is known to-date about how PM emissions are affected by this device. Abbass et al. [12] recorded a reduction in PM mass emissions from a turbocharged $\mathrm{Cl}$ engine with respect to a comparable naturally aspirated engine, but no measurements were taken in terms of number count and size of the particles, which will be crucial parameters for the new Euro-VI limits. Furthermore, research has drawn attention on the role of dilution of the exhaust gas prior to measurement on PM number count. Dilution during sampling of the exhaust gas is required in order to avoid the clogging of the instrument, and to replicate dilution as this gas leaves the tailpipe and is dispersed in the atmosphere [13]. Nonetheless, dilution of exhaust gas can have an impact on PM number concentrations because of phenomena like fragmentation and/or agglomeration [14], heteromolecular nucleation of Soluble Organic Fraction (SOF) onto ashes, sulphuric acid and water vapour [15], and electrostatic interactions due to residual ionisation charges from combustion, enhancing particle interactions [16]. As a result, the PM particle size distributions may change not because of engine combustion or due to the influence of gas-handling devices along the exhaust line, but because of additional processes along the sampling lines which are unrelated with the vehicular installation. This as well has the potential to overor under-estimate the emission characteristics of an engine during emission testing and Type Approval.

Hence, the main goal of this work is to analyse the influence of the exhaust gas turbocharger on nano-scale PM number count from a GDI engine by comparing the number concentration emissions before and after the turbine. Comparison of these measurements will enable to understand the impact of the turbocharger on PM number count, on particle sizes, and on total PM volume, over a wide range of engine operating conditions. In parallel, the influence of exhaust dilution ratio over the PM emissions measurements will be investigated, and the impact of the turbocharger will also be assessed as dilution conditions are changed.

\section{EXPERIMENTAL APPARATUS}

\subsection{Engine}

A Euro-IV compliant, 1.6-L, four-cylinder in-line, wall-guided GDI, turbocharged and intercooled spark ignition engine is used in this study. The maximum fuel injection pressure is $120 \mathrm{bar}$. The engine is always operated in homogeneous charge mode for all the test points under analysis. Detailed specifications of the engine are listed in Table 1. The engine is installed on a Schenck W150 eddy current dynamometer with a CADET V12 engine dynamometer control system, which maintains the engine speed within \pm 2 rpm and the engine load within $\pm 1 \mathrm{Nm}$ in order to allow accurate steady state measurements. The engine was fuelled with commercially-available unleaded gasoline, and fuel consumption is monitored by means of a gravimetric fuel measuring system. Fuel from the same batch is used for all experiments. In-cylinder pressure is measured by means of a piezoelectric pressure transducer, and combustion is monitored with AVL IndiCom software. Figure 1 represents a schematic of the experimental apparatus and layout. 


\section{FIGURE 1}

\subsection{Particulate Measuring System}

The engine test cell is equipped with a fast-response Differential Mobility particle Spectrometer (DMS) Cambustion DMS-500 for engine-exhaust nano-scale particle measurement. It provides a particle size distribution spectrum, i.e. a number concentration spectrum as a function of particle size, for both solid and non-solid particles for diameters between 5 and $1000 \mathrm{~nm}$ [17]. A complete size range scan takes $300 \mathrm{~ms}$, hence the instrument can be used for real-time exhaust measurements. Integration of the spectrum provides the total PM number count per unit volume of raw exhaust gas. For the purposes of this study the size range was split into two separate categories, for particles between 5 and $50 \mathrm{~nm}$, and for those between 50 and $1000 \mathrm{~nm}$. Such classification was chosen to represent the two main modes of engine PM emission, i.e. nucleation and accumulation modes respectively. Two sampling locations are present along the engine exhaust line, one before the turbocharger inlet, and one right at the turbocharger outlet. A heated selector switch valve, maintained at $190^{\circ} \mathrm{C}$, allows the user to cho ose the sampling location, pre- or post-turbocharger.

Within the DMS-500 there are two dilution stages. Primary Dilution Ratio (DR1) is kept constant at 5, while the secondary dilution (DR2) at constant temperature can be varied between 20 and 500, or turned off to 1 . In order to reduce the likelihood of vapour condensation and nucleation, the sampling line is operated at constant partial vacuum ( $250 \mathrm{mbar})$ and heated at high temperature $\left(150{ }^{\circ} \mathrm{C}\right)$. The exhaust gas sample is hence rapidly taken to the measurement temperature, reducing the likelihood of thermophoresis [18]. The tendency of PM to agglomerate along the sampling line is minimised by the fact that the first dilution is performed directly at the sampling point, thus the particulate concentration is decreased from the beginning, and a rapid transition time along the line reduces the residence time, thus lowering the chances for agglomeration further. In addition, issues related to static electricity are prevented using electrically conductive tubes in the sampling lines. The DMS was traceably calibrated by the equipment manufacturer for size and number against span aerosols with standard polystyrene latex spheres, SOF and soot through comparison with a differential mobility analyser for several aerosol concentrations. A traceable standard electrometer was used for number calibration using the methodology that is recommended for condensation particle counter calibration in the European Particulate Measurement Programme (PMP) [19-20]. Measured PM number concentrations always fell within the instrument calibration range.

\section{METHODOLOGY}

All experiments are performed at steady state after a complete warm-up which lasts for 20 minutes to allow for oil and coolant temperatures stabilisation (363K for the water and $378 \mathrm{~K}$ for the oil approximately) [21]. PM number count measurements are taken sequentially before and after the turbocharger for every test point. The measurement duration is chosen in order to capture the natural variability of PM number emissions from the engine, for a minimum test duration of 5 minutes. The particle size distribution is then averaged over the duration of the measurement to yield a plot of mean spectral concentration versus particle diameter. For repeatability analysis, three independent measurements are taken at both sampling locations (before and after the turbocharger) on separate days for each test point. In line with the PMP, the Coefficient of Variation (CoV) on total number count is used to quantify repeatability [1920].

\subsection{Fixed Dilution Conditions Experiments}

A matrix of 12 operating points was tested, at a fixed dilution ratio of 125 (DR1 = 5, DR2 = 25). Three engine speeds, 1500, 2500 , and $3500 \mathrm{rpm}$, and four engine loads, 20,50, 80 , and $110 \mathrm{Nm}$, were chosen. The actual test sequence was randomised in factorial experiments in order to minimise parasitic or inter-relation effects [22]. For all test conditions, whether there are statistically-relevant differences between pre- and post-turbocharger is assessed by means of a hypothesis test on the differences between pre- and postturbocharger particle size distributions at a 95\% confidence interval [22]. The particle size distributions are discretised in 38 bins or ranges for particle sizes. The hypothesis test is therefore implemented on the differences between the number concentrations from homologous size classes. The variations in emission characteristics across the turbocharger are then quantified in terms of the total number concentration, of the Count Mean Diameter (CMD), and of PM volume. These parameters are related by 


$$
V_{P M}=\sum_{i=1}^{k} n_{k} \times \frac{4}{3} \pi\left(\frac{d_{C M D_{k}}}{2}\right)^{3}
$$

where the summation extends to all $\boldsymbol{k}=38$ size classes within the DMS output, $\boldsymbol{n}_{\boldsymbol{k}}$ is the number concentration per class, and $\boldsymbol{d}_{\boldsymbol{C M} \boldsymbol{D}_{\boldsymbol{k}}}$ is the CMD per class. A study by Symonds et al. [23] comparing PM from Cl and GDI engines showed that particles from GDI engines are more spherical than those emitted by $\mathrm{Cl}$ engines, hence the adoption of $\boldsymbol{d}_{C M D_{k}}^{3}$ to estimate the PM volume. By assigning a reference constant density to the particles, the estimate of PM volume can be turned into a mass estimate, since most of the mass emissions are due to the larger soot particles, which are in the solid phase.

\subsection{Variable Dilution Conditions Experiments}

For the $1500 \mathrm{rpm}, 80 \mathrm{Nm}$ engine operating condition, further tests were performed at both sampling locations before and after the turbocharger while varying exhaust dilution, at $5(\mathrm{DR} 1=5, \mathrm{DR} 2=1)$ and $100(\mathrm{DR} 1=5, \mathrm{DR} 2=20)$. These two experiments add to the test from the fixed dilution experiments for the same operating condition at DR = 125 (DR1 = 5, DR2 = 25). The same hypothesis test on differences is performed twice. The first test checks whether the use of different dilution ratios induces variations in the PM number count that are measured at the same sampling location. To do this, pair-wise comparisons on particle size distributions from the same sampling point with different dilutions are made for both pre- and post-turbocharger locations. The second test aims at checking whether the detected differences across the turbocharger are significant regardless of the dilution conditions, and it is implemented on particle size distributions before and after the turbocharger with the same dilution.

\section{RESULTS AND DISCUSSION}

\subsection{Fixed Dilution Conditions}

Repeatability for the fixed dilution experiments is expressed as the CoV on the total PM number count from three independent repetitions of every point of the matrix and for both sampling locations. On average for fixed dilution experiments, CoV of $17.7 \%$ is obtained, well in line with results from other researchers in the recent years [3,21,24]. The hypothesis test on differences between particle size distributions measured before and after the turbocharger for all operating conditions at fixed dilution aimed at understanding whether it is possible to reject the null hypothesis of equal emission spectra at the two sampling locations. The results from this test are shown in Table 2. For most cases, a positive outcome is obtained; hence we can reject the null hypothesis of equal PM number counts and believe at a 95\% confidence level that the turbocharger does have a statistically relevant influence on PM number emissions. Furthermore, when a negative output is obtained it is because there is not a substantial change between total emissions across the turbocharger, but a minor variation in the shape of the particle size distribution functions. In other words, the sizedependent number counts are different across the turbocharger, but the total emissions do not differ substantially.

\section{TABLE 2}

Figure 2 shows the percentage variation (post-turbine with respect to pre-turbine) in total number count ( $z$-axis) as a function of engine speed ( $x$-axis) and load ( $y$-axis). In this and in all successive plots, the percentage variation is calculated as

$$
\% \Delta x=\frac{x_{\text {postTC }}-x_{\text {preTC }}}{x_{\text {preTC }}}
$$

where $x$ is any parameter of interest. In terms of absolute change in number count, in order to display both positive and negative values on a logarithmic scale, the following transformation is adopted

$$
\Delta N / c c_{l o g}=\operatorname{sign}(\Delta N / c c) \times \log _{10}(|\Delta N / c c|)
$$

which preserves both sign and order of magnitude of the change. Figure 3, in a similar fashion with respect to Figure 2 , shows the logarithmic change in total PM number concentration emissions for all test points under fixed dilution conditions. 
Both plots show that there is a much stronger dependence of the variation in number count on engine load rather than engine speed. The variation is initially negative $\left(\Delta N \sim-10^{6} \mathrm{~N} / \mathrm{cc}\right)$, indicating that fewer particles are present downstream of the turbocharger than upstream, but as load increases, the situation is reversed and the exhaust gas after the turbine gets richer in particles $\left(\Delta N \sim+10^{6} N /\right.$ $c c$ ). At low load PM levels downstream of the turbocharger are halved with respect those upstream of the turbine, while at higher load there are almost three times more particles after the turbocharger than there were at its inlet.

The PM volume percentage variation, calculated with Equations (1) and (2), is shown in Figure 4. For this parameter as well there is a much stronger dependence on engine load rather than speed, and there is a positive slope with respect to engine load. This graph indicates that at higher engine load, not only are particles between 5 and $1000 \mathrm{~nm}$ diameter more numerous as shown in Figures 2 and 3 , but they also occupy more volume after the turbine than before $(+234.6 \%)$, while at low load volumes are comparable. Since a reduction in number concentration was detected at low load in Figure 3, and a slight increase is noticed in PM volume in the same operating range, this means that overall an increment in particle size to some extent is to be expected in order to maintain the balance.

If we translate the volume analysis into the mass domain by assuming constant reference density, this means that, within the DMS measurement band (5 to $1000 \mathrm{~nm}$ ), the mass of PM increases across the turbocharger with increasing engine load. For this to happen, new particles have to be borne because of nucleation $[9,25]$ and/or particles larger than $1000 \mathrm{~nm}$ have to undergo fragmentation and become visible within the resolution of the instrument after the turbocharger. These hypotheses seem plausible because, given the dependence of volume on $d_{C M D}^{3}$ as in Equation (1), the increment in volume must come mostly from the larger accumulation-mode particles, whereas the increment in particles number must come mostly from enhanced nucleation.

\section{FIGURE 2}

\section{FIGURE 3}

\section{FIGURE 4}

A more detailed insight in the phenomena taking place can be obtained by the analysis of nucleation and accumulation modes separately. Figure 5 shows the logarithmic variation in number emissions for both modes. Changes in nucleation-mode (5 - $50 \mathrm{~nm}$ ) particle concentration reflect what was seen for the total emissions in Figure 3, with a reduction in particle number $\left(\Delta N \sim-10^{6} \mathrm{~N} / c c\right)$ followed by a comparable increment $\left(\Delta N \sim+10^{6} \mathrm{~N} / c c\right)$ as the engine load increases. This is expected since nucleation-mode particles account for most of the number emissions. For accumulation-mode particles (50 - $1000 \mathrm{~nm}$ size) instead, apart from an individual case at $1500 \mathrm{rpm}$ engine speed, $20 \mathrm{Nm}$ engine load, there is a systematic increment in their number concentration downstream of the turbocharger. In terms of CMD in Figure 6, for nucleation-mode particles the mean diameter initially decreases with load, up to $-37.9 \%$ at $2500 \mathrm{rpm}$ engine speed, $80 \mathrm{Nm}$ engine load, and then increases up to $+19.9 \%$ at $3500 \mathrm{rpm}$ engine speed, $110 \mathrm{Nm}$ engine load, while for accumulation-mode particles a slight increment (+3.6\%) throughout the matrix is recorded. In terms of PM volume in Figure 7, calculated by means of Equation (1), for nucleation-mode particles the reduction in their concentration at low engine load, coupled with a slight reduction in their CMD, translates into a reduction in the PM volume they occupy, with a minimum of $-59.7 \%$ at $3500 \mathrm{rpm}$ engine speed, $20 \mathrm{Nm}$ engine load, while the volume increment at higher load follows directly from their augmented number concentration and mean diameter, topping at $+394.5 \%$ at $3500 \mathrm{rpm}$ engine speed, $110 \mathrm{Nm}$ engine load. For all operating points there is an increment in volume associated to accumulation particles, and this change gets stronger with engine load, with a maximum increase of $+233.0 \%$ at $3500 \mathrm{rpm}$ engine speed, $110 \mathrm{Nm}$ engine load. Once again, this was expected since accumulation-mode particles account for most of the mass emissions, hence for most of PM volume.

FIGURE 5a and 5b

FIGURE $6 a$ and $6 \mathrm{~b}$ 
It is thought that a series of phenomena concur in order to lead to these results. As injection pressure and duration increase with engine load, a larger share of SOF in the exhaust is produced [26] and as gases expand through the turbine, nucleation of SOF is promoted, resulting in more numerous nucleation-mode particles at the turbine outlet [27]. On the other hand, when injection pressure and duration are smaller at low engine load, a net reduction of nucleation-mode particles is observed due to predominant particle sticking and agglomeration driven by the centrifugal action of the turbine [28]. At the same time, for the concentration of accumulation-mode particles to increase systematically throughout the matrix, some nucleation particles coalesce and become bigger so that they migrate into the $50-1000 \mathrm{~nm}$ diameter spectrum. This complements the reduction in nucleation-mode number emissions and volume at low load in Figures 5 and 7 . In addition, at higher engine load some micro-scale particles $\left(d_{p}>1000 \mathrm{~nm}\right)$ can undergo fragmentation as they interact with the turbine [29]. Fragmentation becomes stronger as heavier particles may not follow the gas flow [16], and so does centrifugal agglomeration as the driving force is proportional to the angular velocity squared [30]. The CMD for this class size in Figure 6 shows on average a slight increment $(+3.6 \%)$, which is in line with the balance given by the tendency of agglomeration into larger clusters, and the combined effect of migration of smaller nucleation particles into the accumulation spectrum and fragmentation of micro-scale particles. 


\subsection{Variable Dilution Conditions}

The largest percentage variation in PM number count levels across the turbine $(+296.5 \%)$ was found to occur at the engine speed of $1500 \mathrm{rpm}$ and $80 \mathrm{Nm}$ engine load and therefore, this operating point was chosen as a test point for evaluating the effect of variable dilution ratio on PM number count. Two different dilution ratios were studied: $D R$ of $5(D R 1=5, D R 2=1)$ and DR of $100(D R 1=5$, $D R 2=20)$, in addition from the original experiment at $D R=125(D R 1=5, D R 2=25)$. Repeatability, expressed as CoV on total emissions from three independent repeats, has an average value of $25.4 \%$, indicating that dispersion in total number emissions under these test conditions is well within one order of magnitude, in line with results obtained from other researchers in the recent years $[3,21,24]$. The first hypothesis test on differences is now implemented in order to check whether the use of different dilution ratios induces variations in the PM number emission levels that are measured at the same sampling location. To do this, pair-wise comparisons are made for both pre- and post-turbocharger, and the results are shown in Table 3 . As most outcomes are positive, it is possible at a 95\% confidence level to reject the null hypothesis of null influence of dilution on PM number count measurements, and believe that for most cases changes in dilution conditions have a significant impact on the measured PM number concentration levels both before and after the turbine. For the individual test where the output was negative, once again it is the case that the sizedependent number emissions are different across the turbocharger, but the total emissions do not differ substantially. These results are therefore in agreement with literature discussing the influence of exhaust dilution on the magnitude of PM number emission levels $[15,31,32]$.

\section{TABLE 3}

The second test aimed at checking whether the detected differences across the turbocharger are significant regardless of the dilution conditions. Table 4 shows that indeed the influence of the turbocharger is statistically relevant at $95 \%$ confidence level independently of the dilution ratio adopted. This is a very remarkable result because it emphasizes that despite changes in the measured emission levels due to dilution, the impact of the turbocharger cannot be neglected.

\section{TABLE 4}

Figure 8 shows on a logarithmic $y$-axis the absolute PM number count, both before and after the turbine, for all dilution conditions. The overall result is that as DR is enlarged, i.e. the exhaust gas sample becomes more diluted, the PM number count of nucleation-mode particles is largely impacted, resulting in a net increment in their number concentration of one order of magnitude. This is in line with the results previously obtained by Whelan et al. [21]. An explanation for this phenomenon can be given in light of the effect of dilution on the rate of particle nucleation. Gas dilution results in a lower surface area per unit volume for SOF condensation over existing solid particles, and their resulting higher supersaturation leads to homogeneous nucleation of the volatile material [33,34]. All experiments converge on the fact that total number concentrations increase across the turbocharger and thus the turbine does influence PM number count, as proven in Table 4. Nonetheless, the magnitude of this influence does change with dilution and is driven by the trends for the nucleation-mode particles, which account for most of the number population. These results stress once more the fact that dilution conditions do have an impact on the measurements but they do not seem to alter the physical phenomena that those particles experience across the turbocharger. The influence of the turbocharger is still significant regardless of the dilution conditions adopted.

\section{FIGURE 8}




\section{CONCLUSIONS}

This work investigated the influence of the exhaust gas turbocharger on nano-scale PM number emission levels from a GDI engine, and assessed the role of exhaust dilution on PM emissions measurement. From the outcomes of the experiments that were carried out, the following conclusions can be drawn.

1. From the tests at fixed dilution ( $D R=125)$, repeatability on three independent measurements at both sampling locations under fixed dilution was assessed at an average $\mathrm{CoV}$ of $17.7 \%$, for both pre- and post-turbocharger locations throughout the matrix of test points at 1500, 2500, and 3500 rpm engine speed, and 20,50, 80 and $110 \mathrm{Nm}$ engine load. This value is in line with the outcomes from other researchers in recent years.

2. Hypothesis test on differences between total PM number count before and after the turbocharger at every operating point at fixed dilution proved that for most cases there are indeed statistically relevant differences between the two sampling locations, at a 95\% confidence level. It is conjectured that the differences in PM number count are to be attributed to particle nucleation as the exhaust gas expands across the turbine, particle sticking to the turbine rotor and impact-driven fragmentation, and particle agglomeration and growth across the turbine. These phenomena would explain both the reduction in total PM particles number count at low engine load without a corresponding reduction in volumes (limited nucleation, predominant particle sticking and agglomeration), and the increment of both PM number emission levels and volumes at high engine load (enhanced nucleation and agglomeration, and even fragmentation of micro-scale particles).

3. Changes in dilution ratio affect repeatability of total PM number emissions from three independent tests only to a minor extent. Experiments at $1500 \mathrm{rpm}$ engine speed, $80 \mathrm{Nm}$ engine load with DR of 5, 100, and 125, at both sampling locations, show an average CoV of $25.4 \%$ on total PM number count levels, which means that dispersion in test data is sensibly below one order of magnitude.

4. Hypothesis tests on the variable dilution conditions experiments showed that on the one hand for most cases changes in dilution conditions result in systematically different total number concentrations observed at the same sampling location, at a 95\% confidence level. On the other hand, regardless of the changes in dilution, the impact of the turbocharger on relative pre-post PM total number count is always significant at a 95\% confidence level, hence the influence of the turbocharger on nano-scale PM number count cannot be neglected.

\section{REFERENCES}

[1] Peckham, M.S; Finch, A; Campbell, B; Price, P. and Davies, M.T. (2011), "Study of Particle Number Emissions from a Turbocharged Gasoline Direct Injection (GDI) Engine Including Data from a Fast-Response Particle Size Spectrometer", SAE International 2011-01-1224. 10.4271/2011-01-1224.

[2] Price, P; Stone, R; Oude Nijeweme, D. and Chen, X. (2007), "Cold Start Particulate Emissions from a Second Generation DI Gasoline Engine", SAE International 2007-01-1931. 10.4271/2007-01-1931.

[3] Whelan, I; Samuel, S. and Hassaneen, A. (2010), "Investigation into the Role of Catalytic Converters on Tailpipe-out Nano-Scale Particulate Matter from Gasoline Direct Injection Engine", SAE International 2010-01-1572. 10.4271/2010-01-1572.

[4] Davidson, C.I; Phalen, R.F. and Solomon, P.A. (2005), "Airborne Particulate Matter and Human Health: A Review", Aerosol Science and Technology, Vol. 39 No. 8, pp. 737-749. 10.1080/02786820500191348.

[5] Whelan, I; Samuel, S. and Hassaneen, A. (2010), "The Effect of Fuel Temperature on Particulate Matter Formation in Gasoline Direct-Injection Engines”, SAE Int. J. Fuels Lubr., Vol. 3 2010-01-1469, pp. 67-76. 10.4271/2010-01-1469.

[6] European Commission (2007), Regulation (EC) No 715/2007 of the European Parliament and of the Council of 20 June 2007 on Type Approval of Motor Vehicles with Respect to Emissions from Light Passenger and Commercial Vehicles (Euro 5 and Euro 6) and on Access to Vehicle Repair and Maintenance Information.

[7] European Commission (2008), Commission Regulation (EC) No 692/2008 of 18 July 2008 Implementing and Amending Regulation (EC) No 715/2007 of the European Parliament and of the Council on Type-Approval of Motor Vehicles with Respect to Emissions from Light Passenger and Commercial Vehicles (Euro 5 and Euro 6) and on Access to Vehicle Repair and Maintenance Information.

[8] European Commission (2012), Commission Regulation (EU) No 459/2012 of 29 May 2012 Amending Regulation (EC) No 715/2007 of the European Parliament and of the Council and Commission Regulation (EC) No 692/2008 as Regards Emissions from Light Passenger and Commercial Vehicles (Euro 6).

[9] Kittelson, D.B. (1998), "Engines and Nanoparticles: A Review", Journal of Aerosol Science, Vol. 29 5-6, pp. 575-588. 10.1016/S0021-8502(97)10037-4.

[10] Berndorfer, A; Breuer, S; Piock, W. and Bacho, P. von (2013), "Diffusion Combustion Phenomena in GDi Engines caused by Injection Process", SAE International 2013-01-0261. 10.4271/2013-01-0261. 
[11] Piock, W; Hoffmann, G; Berndorfer, A; Salemi, P. and Fusshoeller, B. (2011), "Strategies Towards Meeting Future Particulate Matter Emission Requirements in Homogeneous Gasoline Direct Injection Engines", SAE Int. J. Engines, Vol. 4 2011-01-1212, pp. 1455-1468. 10.4271/2011-01-1212.

[12] Abbass, M.K; Andrews, G.E; Ishaq, R.B; Williams, P.T. and Bartle, K.D. (1991), "A Comparison of the Particulate Composition Between Turbocharged and Naturally Aspirated DI Diesel Engines", SAE International No. 910733. 10.4271/910733.

[13] Kayes, D. and Hochgreb, S. (1998), "Investigation of the Dilution Process for Measurement of Particulate Matter from SparkIgnition Engines", SAE International No. 982601. 10.4271/982601.

[14] Marshall, J.S. (2007), "Particle Aggregation and Capture by Walls in a Particulate Aerosol Channel Flow", Journal of Aerosol Science, Vol. 38 No. 3, pp. 333-351. 10.1016/j.jaerosci.2007.01.004.

[15] Wu, Y; Clark, N; Carder, D. and Shade, B. (2009), "Nano Particulate Matter Evolution in a CFR1065 Dilution Tunnel", SAE International 2009-01-2672. 10.4271/2009-01-2672.

[16] Cromas, J. (2003), "Particulate Matter Formation Mechanisms in a Direct-Injection Gasoline Engine", Master of Science, University of Madison Wisconsin, 2003.

[17] Cambustion Ltd. (2007), DMS500 Fast Particulate Spectrometer User Manual.

[18] Cambustion Ltd. (2005), DMS-03 Cambustion Application Note - Sampling Engine Exhaust with the DMS500.

[19] Andersson, J; Giechaskiel, B; Muñoz-Bueno, R; Sandbach, E. and Dilara, P. (2007), "Particle Measurement Programme (PMP) Light-Duty Inter-Laboratory Correlation Exercise (ILCE_LD) Final Report", European Commission, Joint Research Centre, Institute for Environment and Sustainability.

[20] Giechaskiel, B; Dilara, P. and Andersson, J. (2008), "Particle Measurement Programme (PMP) Light-Duty Inter-Laboratory Exercise: Repeatability and Reproducibility of the Particle Number Method", Aerosol Science and Technology, Vol. 42 No. 7, pp. 528-543. 10.1080/02786820802220241.

[21] Whelan, I; Timoney, D; Smith, W. and Samuel, S. (2013), "The Effect of a Three-Way Catalytic Converter on Particulate Matter from a Gasoline Direct-Injection Engine During Cold-Start”, SAE Int. J. Engines, Vol. 6 2013-01-1305, pp. 1035-1045. 10.4271/2013-01-1305.

[22] Chatfield, C. (1983), Statistics for Technology: A Course in Applied Statistics, Science paperbacks, Vol. 114, 3rd ed., Chapman and Hall, London, New York.

[23] Symonds, J.P.R; Price, P; Williams, P.T. and Stone, R. (2008), "Density of Particles Emitted from a Gasoline Direct Injection Engine", 12th ETH Conference on Nanoparticles.

[24] Whelan, I; Smith, W; Timoney, D. and Samuel, S. (2012), "The Effect of Engine Operating Conditions on Engine-out Particulate Matter from a Gasoline Direct-injection Engine during Cold-start", SAE International 2012-01-1711. 10.4271/2012-01-1711.

[25] Cole, R.L; Poola, R.B. and Sekar, R.R. (1999), "Gaseous and Particulate Emissions from a Vehicle with a Spark-lgnition DirectInjection Engine", SAE International 1999-01-1282. 10.4271/1999-01-1282.

[26] Puzun, A; Wanchen, S; Guoliang, L; Manzhi, T; Chunjie, L. and Shibao, C. (2011), "Characteristics of Particle Size Distributions about Emissions in a Common-Rail Diesel Engine with Biodiesel Blends", 2011 2nd International Conference on Challenges in Environmental Science and Computer Engineering (CESCE 2011), Vol. 11, pp. 1371-1378. 10.1016/j.proenv.2011.12.206.

[27] Roumeliotis, I. and Mathioudakis, K. (2006), "Analysis of Moisture Condensation during Air Expansion in Turbines", International Journal of Refrigeration, Vol. 29 No. 7, pp. 1092-1099. 10.1016/j.ijrefrig.2006.03.001.

[28] Cortés, C. and Gil, A. (2007), "Modeling the Gas and Particle Flow inside Cyclone Separators", Progress in Energy and Combustion Science, Vol. 33 No. 5, pp. 409-452. 10.1016/j.pecs.2007.02.001.

[29] D'Alessio, A; Barone, A.C; Cau, R; D'Anna, A. and Minutolo, P. (2005), "Surface Deposition and Coagulation Efficiency of Combustion Generated Nanoparticles in the Size Range from 1 to $10 \mathrm{~nm}$ ", Proceedings of the Combustion Institute, Vol. 30 No. 2, pp. 2595-2603. 10.1016/j.proci.2004.08.267.

[30] Pietsch, W. (2002), Agglomeration Processes: Phenomena, Technologies, Equipment, Wiley-VCH, Weinheim.

[31] Foote, E.B; Maricq, M; Sherman, M; Carpenter, D; Guenther, M; Peabody, J; Polster, M; Szente, J. and Loos, M. (2013), "Evaluation of Partial Flow Dilution Methodology for Light Duty Particulate Mass Measurement", SAE International 2013-011567. 10.4271/2013-01-1567.

[32] Giechaskiel, B; Schindler, W; Jörgl, H; Vescoli, V; Bergmann, A. and Silvis, W. (2011), "Accuracy of Particle Number Measurements from Partial Flow Dilution Systems", SAE International 2011-24-0207. 10.4271/2011-24-0207.

[33] Burtscher, H. (2005), "Physical Characterization of Particulate Emissions from Diesel Engines: A Review", Journal of Aerosol Science, Vol. 36 No. 7, pp. 896-932. 10.1016/j.jaerosci.2004.12.001.

[34] Lipsky, E; Stanier, C.O; Pandis, S.N. and Robinson, A.L. (2002), "Effects of Sampling Conditions on the Size Distribution of Fine Particulate Matter Emitted from a Pilot-Scale Pulverized-Coal Combustor", Energy Fuels, Vol. 16 No. 2, pp. 302-310. 10.1021/ef0102014. 


\section{Figure Captions}

Figures: colour on the web only

\begin{tabular}{|c|c|}
\hline Figure & $\begin{array}{c}\text { No. Columns } \\
\text { Fitting }\end{array}$ \\
\hline 1 & $1 / 1.5$ \\
\hline 2 & 1 \\
\hline 3 & 1 \\
\hline 4 & 1 \\
\hline $5(5 a+5 b)$ & $1.5 / 2$ \\
\hline $6(6 a+6 b)$ & $1.5 / 2$ \\
\hline $7(7 a+7 b)$ & $1.5 / 2$ \\
\hline 8 & $1 / 1.5$ \\
\hline
\end{tabular}

Figure 1 - Schematic layout of the test cell.

Figure 2 - Percentage variation in total PM number emissions across the turbocharger for the matrix of test points at fixed dilution.

Figure 3 - Logarithmic variation in total PM number emissions across the turbocharger for the matrix of test points at fixed dilution.

Figure 4 - Percentage variation in total PM volume across the turbocharger for the matrix of test points at fixed dilution.

Figures $5 \mathrm{a}$ and $5 \mathrm{~b}$ - Logarithmic variation in nucleation-mode (a) and accumulation-mode (b) PM number emissions across the turbocharger for the matrix of test points at fixed dilution.

Figures $6 a$ and $6 b$ - Percentage variation in nucleation-mode (a) and accumulation-mode (b) CMD across the turbocharger for the matrix of test points at fixed dilution.

Figures $7 \mathrm{a}$ and $7 \mathrm{~b}$ - Percentage variation in nucleation-mode (a) and accumulation-mode (b) PM volume across the turbocharger for the matrix of test points at fixed dilution.

Figure 8 - Number concentration emissions (nucleation and accumulation modes, and total) for both pre- and post-turbocharger under different dilution conditions. 
Tables

Table 1 - GDI test engine technical specifications.

\begin{tabular}{|l|l|}
\hline Bore & $77.0 \mathrm{~mm}$ \\
\hline Stroke & $85.8 \mathrm{~mm}$ \\
\hline Displacement & $1598 \mathrm{cc}$ \\
\hline Compression Ratio & 10.5 \\
\hline Rated Power & $129 \mathrm{~kW} @ 6000 \mathrm{rpm}$ \\
\hline Rated Torque & $240 \mathrm{Nm} @ 1600-5000 \mathrm{rpm}$ \\
\hline
\end{tabular}

Table 2 - Results of the hypothesis test of significant difference between particle size distributions from pre- and post-turbocharger at fixed dilution conditions ( $\mathrm{Y}=$ there are statistically significant differences, $\mathrm{N}=$ there are not relevant differences -the null hypothesis cannot be rejected-, both at a $95 \%$ confidence interval).

\begin{tabular}{|c|c|c|c|c|}
\cline { 2 - 5 } \multicolumn{1}{c|}{} & \multicolumn{4}{c|}{ Engine Load } \\
\hline Engine Speed & $\mathbf{2 0} \mathbf{~ N m}$ & $\mathbf{5 0} \mathbf{~ N m}$ & $\mathbf{8 0} \mathbf{~ N m}$ & $\mathbf{1 1 0} \mathbf{~ N m}$ \\
\hline $1500 \mathrm{rpm}$ & $\mathrm{Y}$ & $\mathrm{Y}$ & $\mathrm{Y}$ & $\mathrm{Y}$ \\
\hline $2500 \mathrm{rpm}$ & $\mathrm{Y}$ & $\mathrm{Y}$ & $\mathrm{Y}$ & $\mathrm{Y}$ \\
\hline $3500 \mathrm{rpm}$ & $\mathrm{N}$ & $\mathrm{N}$ & $\mathrm{N}$ & $\mathrm{Y}$ \\
\hline
\end{tabular}

Table 3 - Results of the hypothesis test of significant difference between particle size distributions from the same sampling locations for different dilution conditions $(Y=$ there are statistically significant differences, $N=$ there are not relevant differences - the null hypothesis cannot be rejected-, both at a $95 \%$ confidence interval).

\begin{tabular}{|c|c|c|c|}
\cline { 2 - 4 } \multicolumn{1}{c|}{} & \multicolumn{3}{c|}{ Pair-wise Comparisons } \\
\hline \multirow{3}{*}{ Sampling } & $\begin{array}{c}\text { DR }=5 \\
\text { vs } \\
\text { DR }=100\end{array}$ & $\begin{array}{c}\text { DR }=5 \\
\text { vs } \\
\text { DR }=100\end{array}$ & $\begin{array}{c}\text { DR }=100 \\
\text { vs } \\
\text { DR }=125\end{array}$ \\
\hline Pre-TC & Y & $Y$ & $Y$ \\
\hline Post-TC & N & $Y$ & $Y$ \\
\hline
\end{tabular}

Table 4 - Results of the hypothesis test of significant difference between particle size distributions from pre- and post-turbocharger at variable dilution conditions $(\mathrm{Y}=$ there are statistically significant differences, $\mathrm{N}=$ there are not relevant differences -the null hypothesis cannot be rejected-, both at a $95 \%$ confidence interval).

\begin{tabular}{|c|c|c|}
\hline $\mathrm{DR}=5$ & $\mathrm{DR}=100$ & $\mathrm{DR}=125$ \\
\hline $\mathrm{Y}$ & $\mathrm{Y}$ & $\mathrm{Y}$ \\
\hline
\end{tabular}


COMBUSTION ANALYSIS

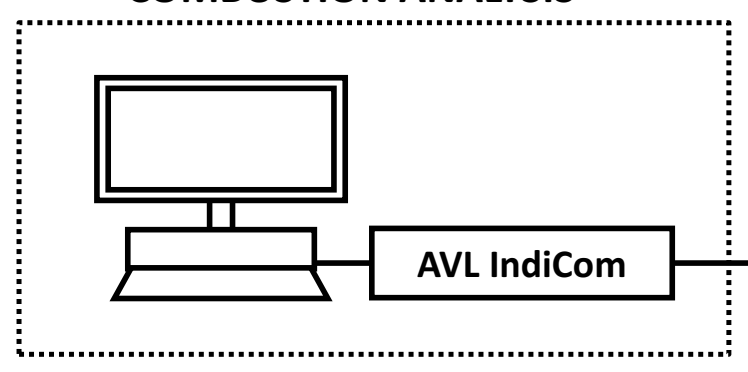

$\vdots$
$\vdots$
$\vdots$
$\vdots$
$\vdots$
$\vdots$
$\vdots$
$\vdots$
$\vdots$

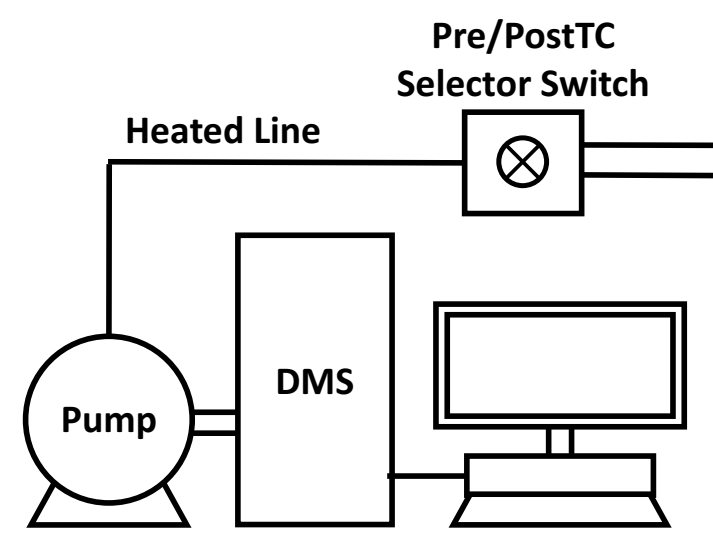

\section{PARTICLE EMISSIONS ANALYSIS}




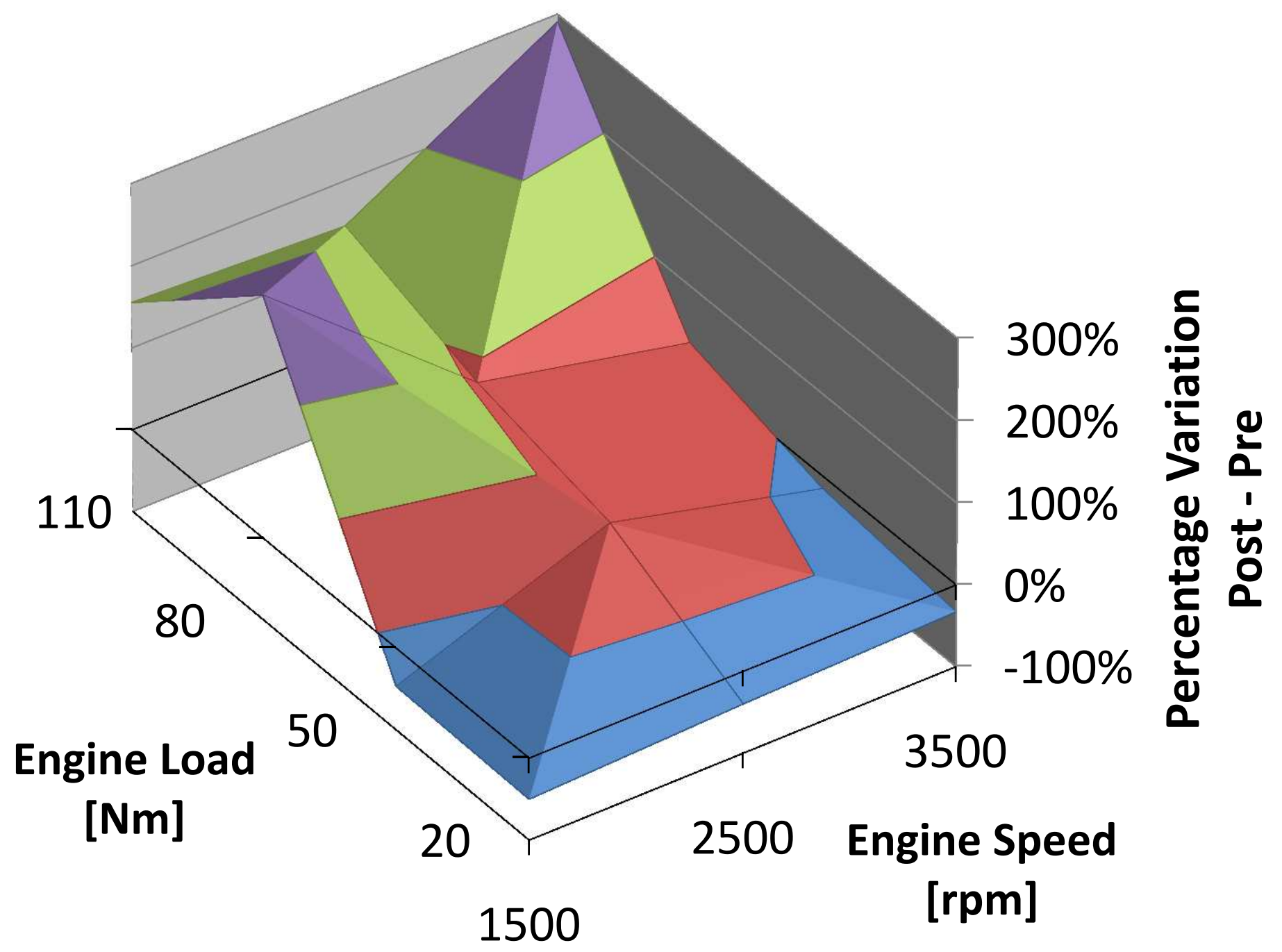

$\square-100 \%-0 \% \square 0 \%-100 \% \quad \square 100 \%-200 \% \square \quad \square 00 \%-300 \%$ 


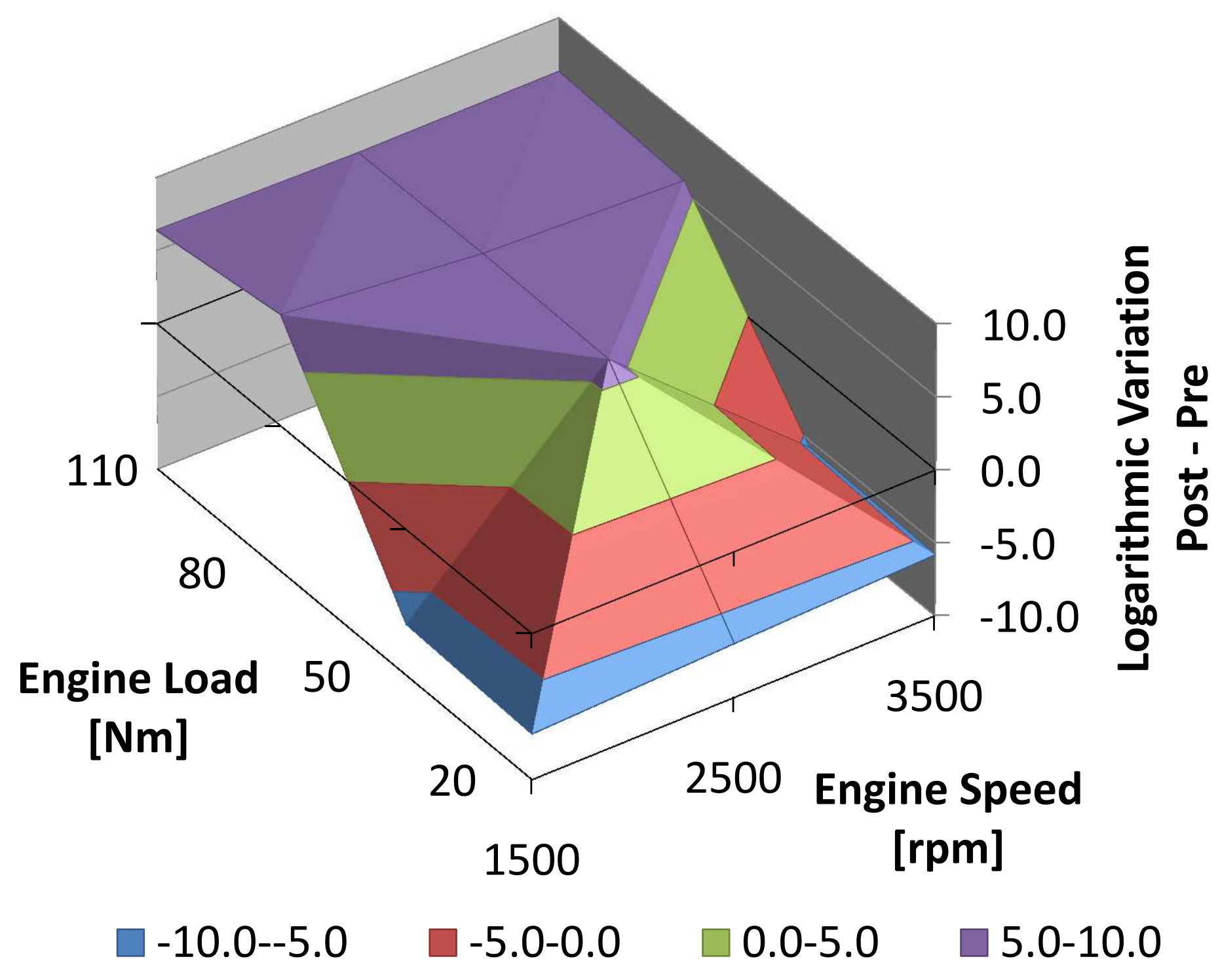




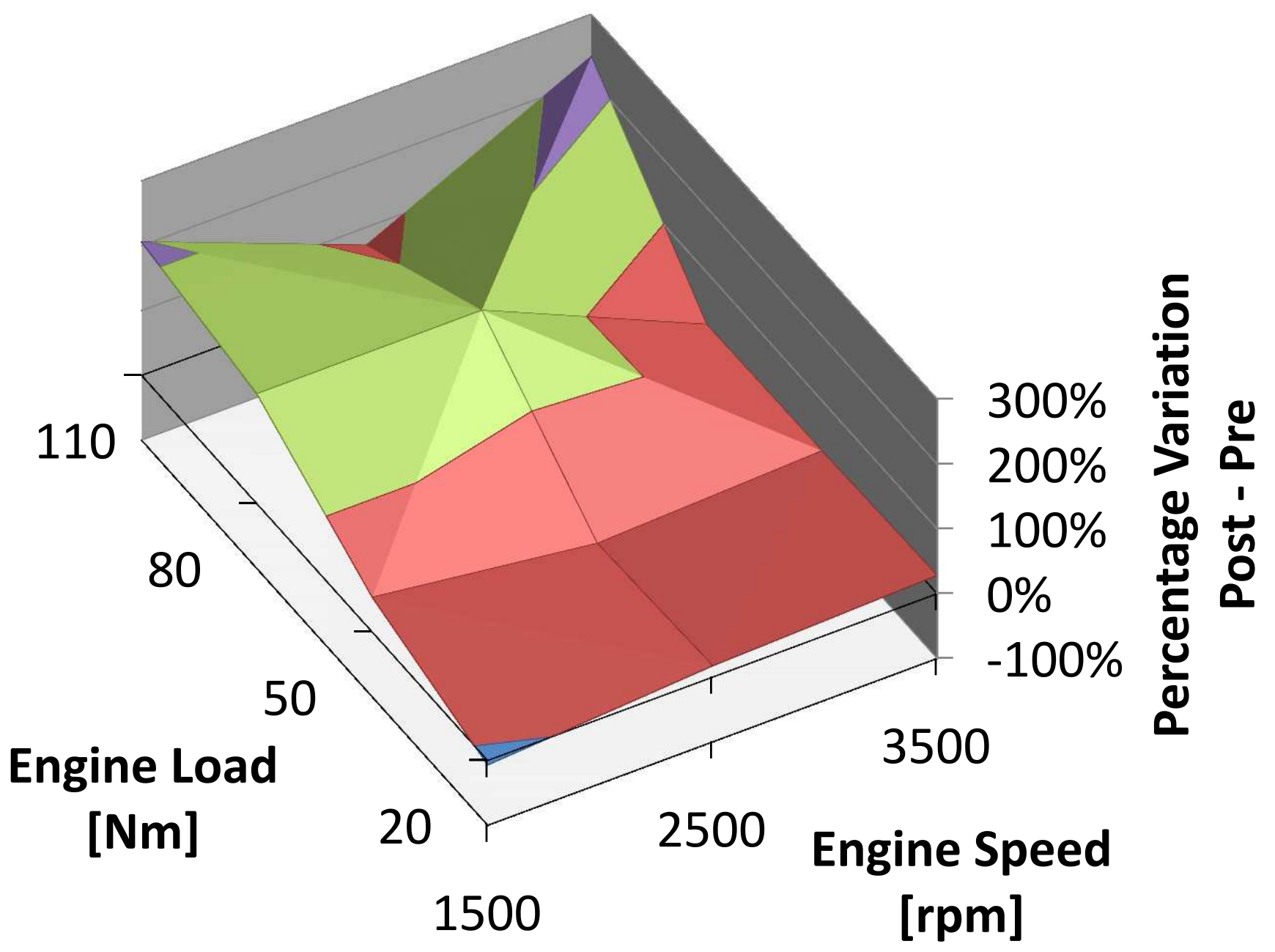

$\square-100 \%-0 \% \quad \square 0 \%-100 \% \quad \square 100 \%-200 \% \quad \square 200 \%-300 \%$ 


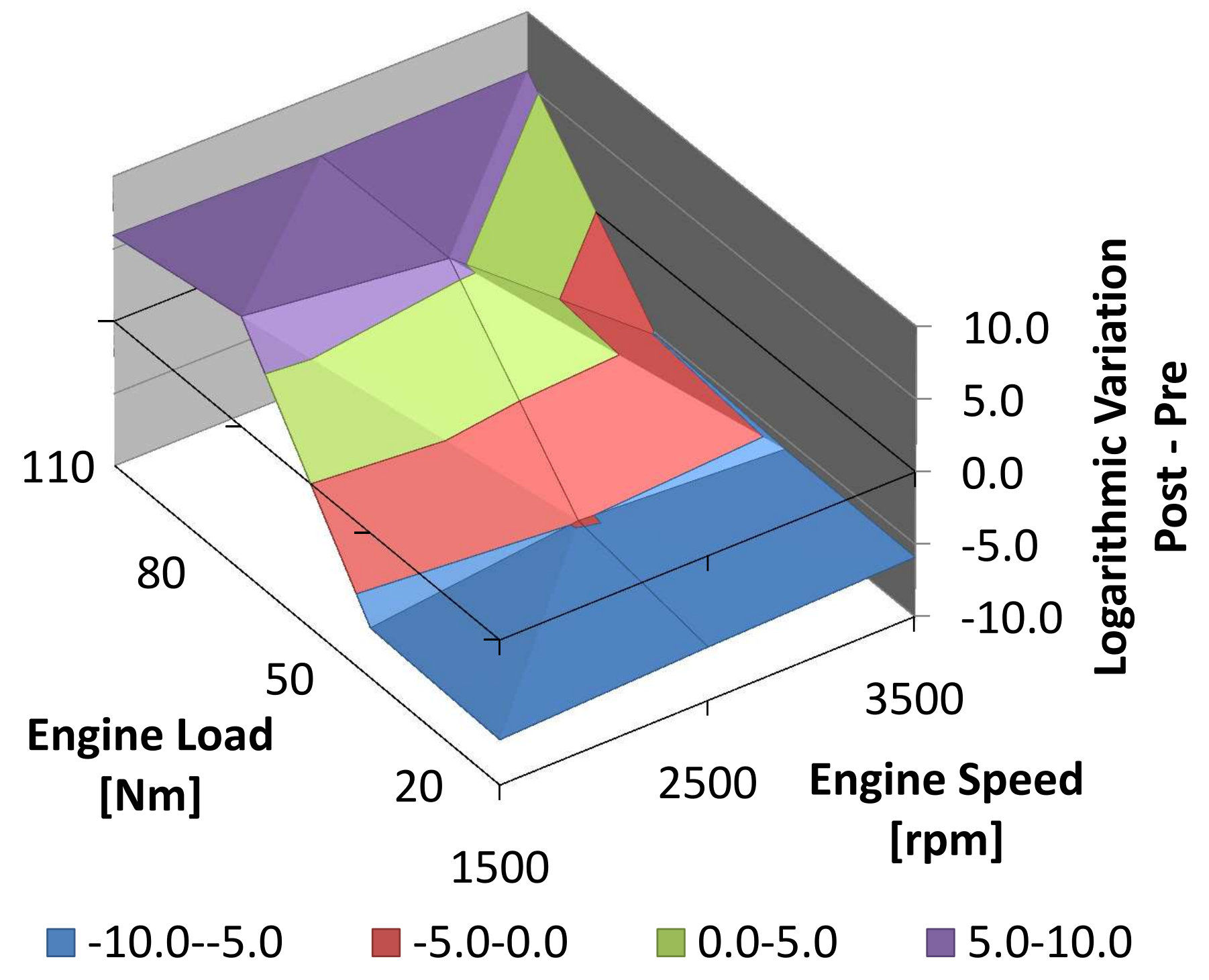




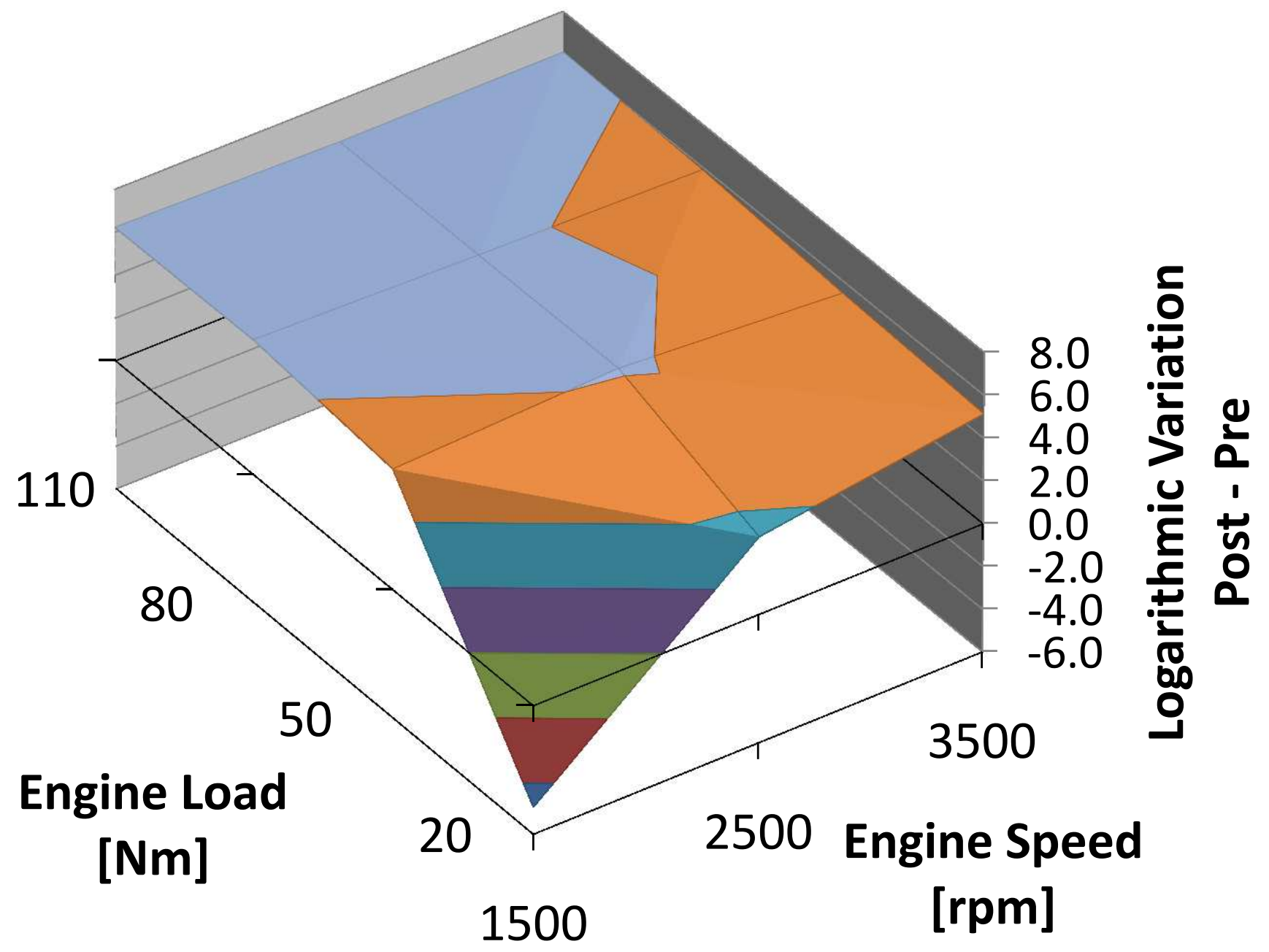

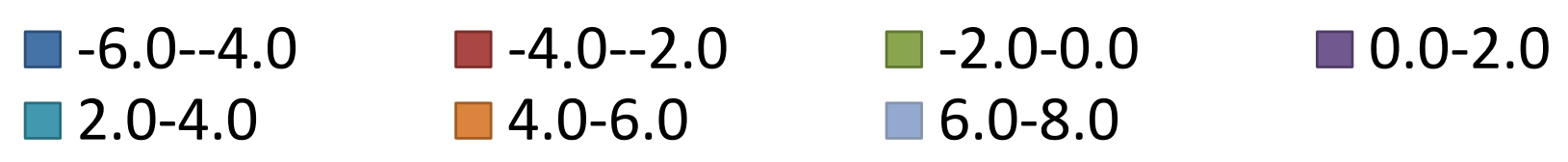




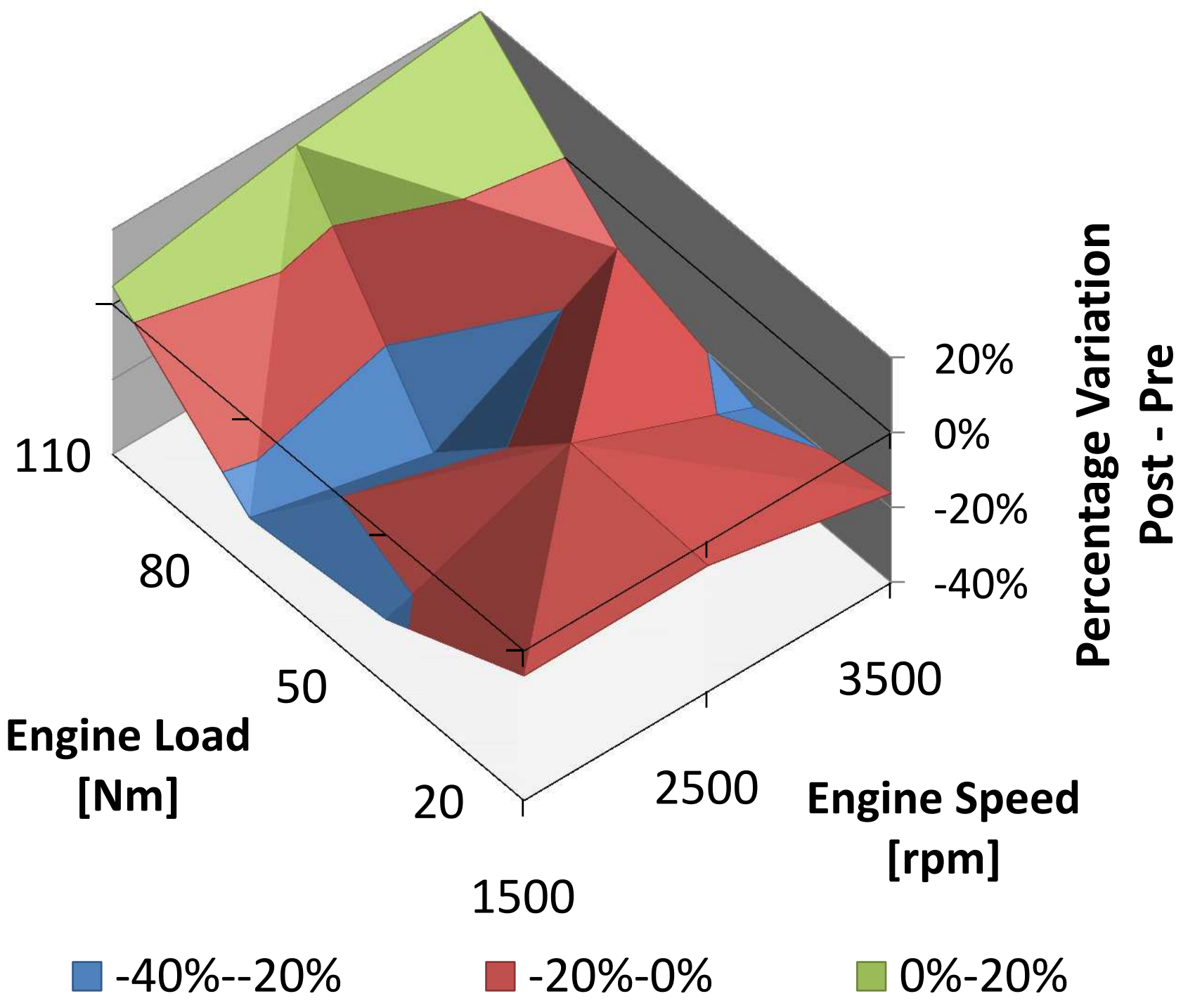




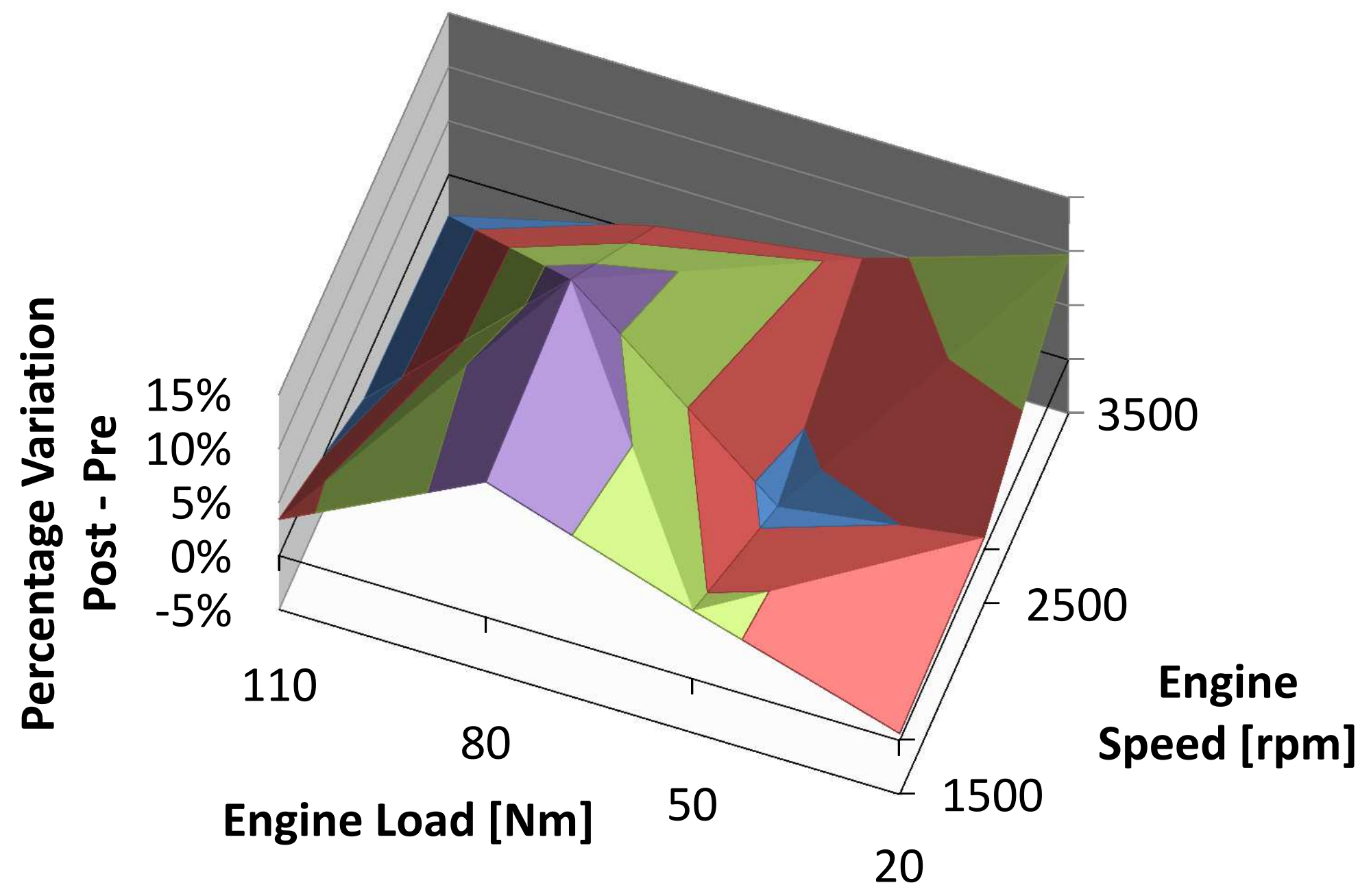

$\square-5 \%-0 \% \square 0 \%-5 \% \quad \square 5 \%-10 \% \square \square 10 \%-15 \%$ 


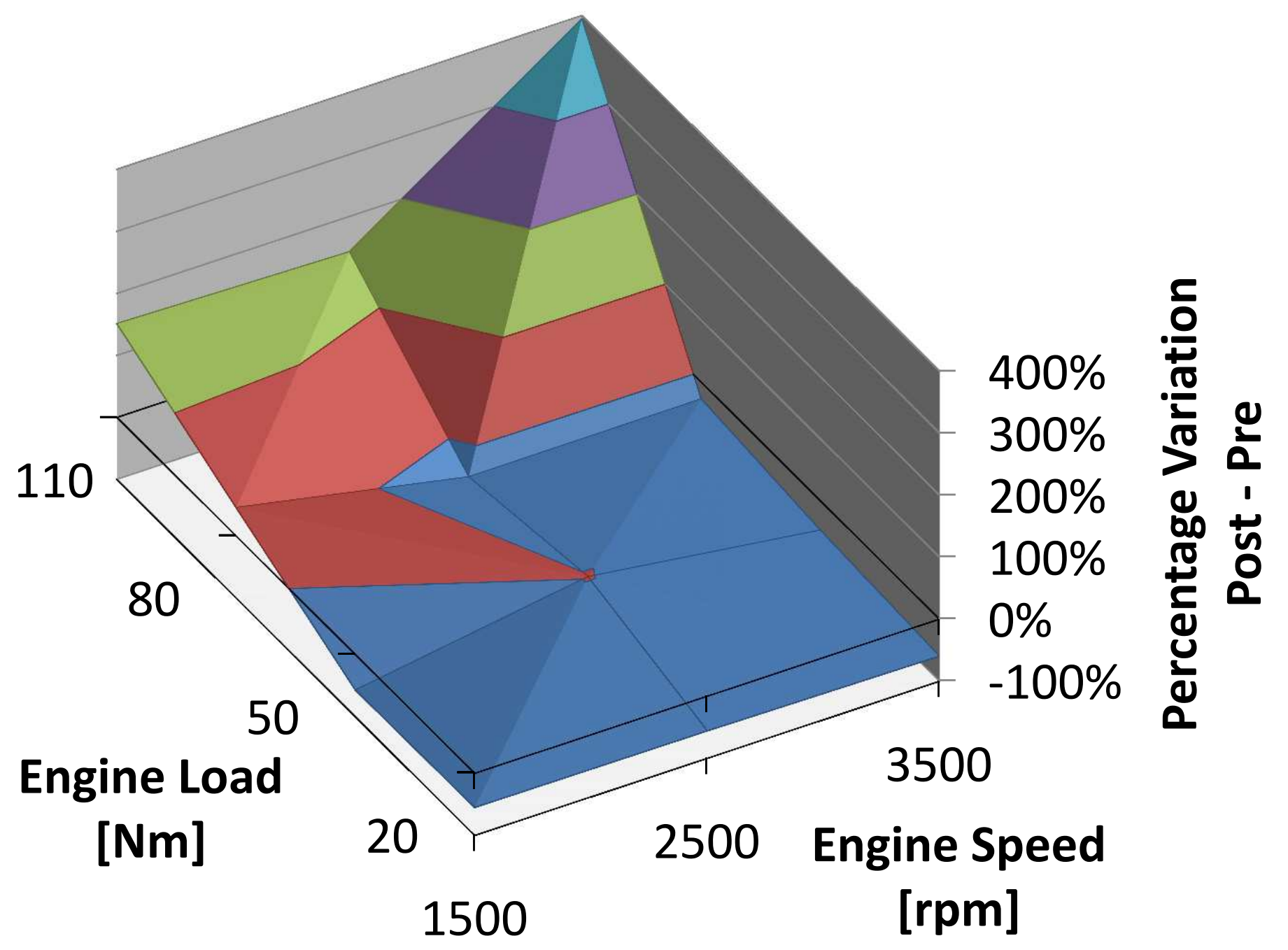

$\square-100 \%-0 \% \quad \square 0 \%-100 \% \quad \square$ 100\%-200\% $\square$ 200\%-300\% $\square 300 \%-400 \%$ 


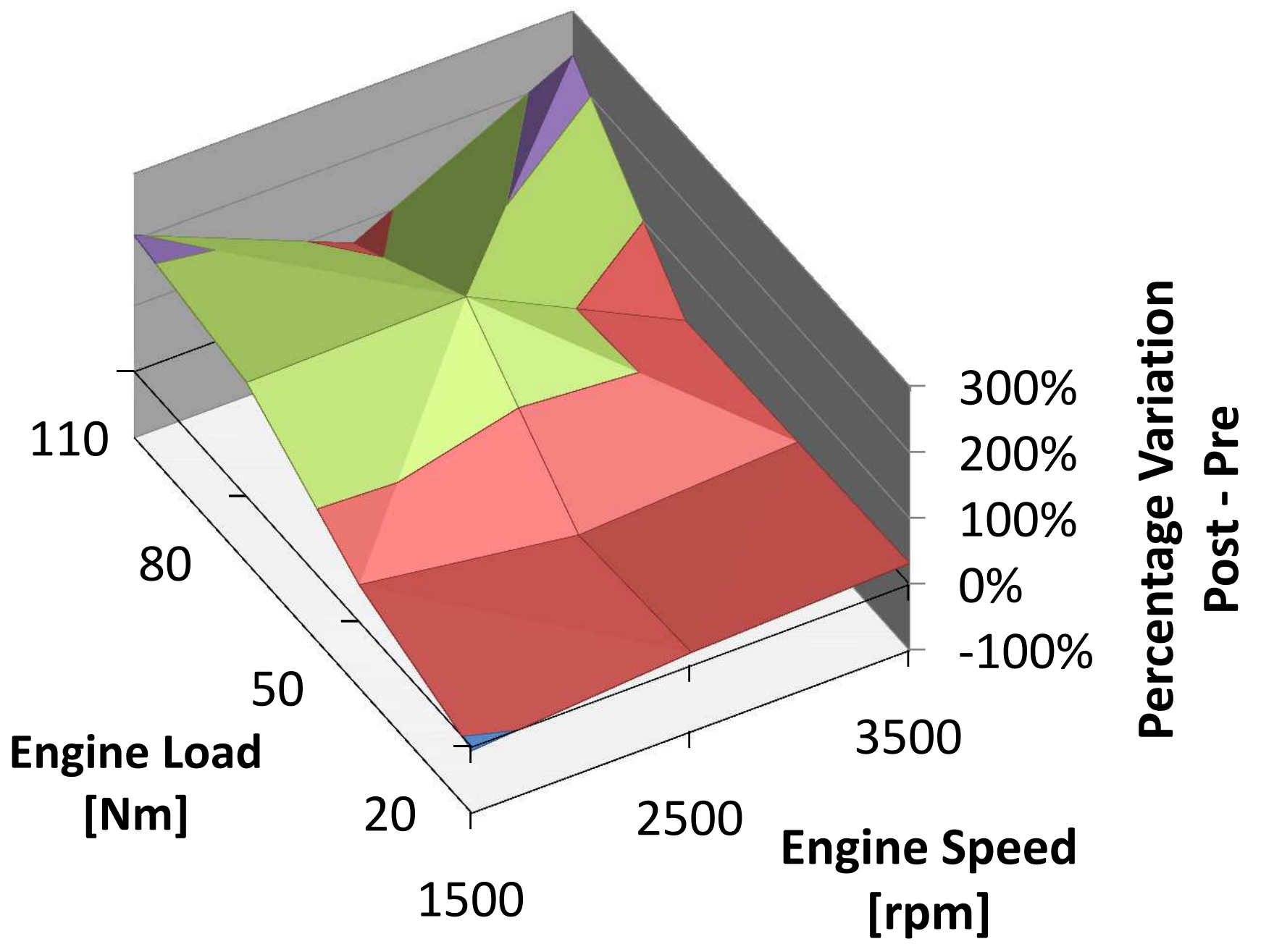

$\square-100 \%-0 \% \quad \square 0 \%-100 \% \quad \square 100 \%-200 \% \quad \square 200 \%-300 \%$ 
Figure 8

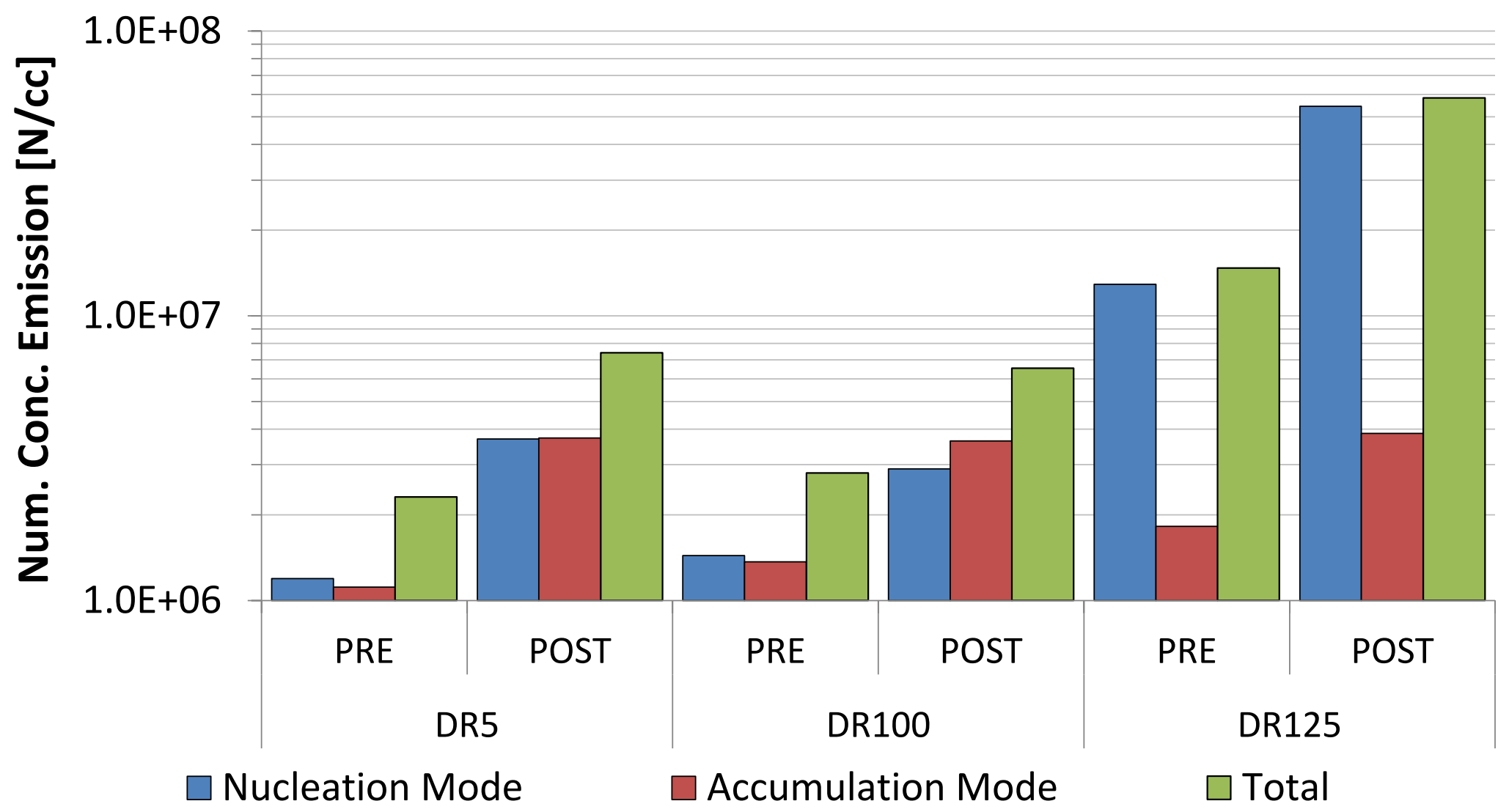

